\title{
The association of frontal recess anatomy and mucosal disease on the presence of chronic frontal sinusitis: a computed tomographic analysis*
}

\author{
Wen-Sen Lai' ${ }^{1,2}$, Pei-Lin Yang ${ }^{3}$, Chiao-Hua Lee ${ }^{4}$, Yuan-Yung Lin', Yueng- \\ Hsiang Chu', Chih-Hung Wang ${ }^{1}$, Hsing-Won Wang ${ }^{1,5}$, Cheng-Ping Shih \\ 1 Department of Otolaryngology-Head and Neck Surgery, Tri-Service General Hospital, National Defense Medical Center, Taipei, \\ Taiwan \\ 2 Department of Otolaryngology-Head and Neck Surgery, Taichung Armed Forces General Hospital, Taichung, Taiwan \\ ${ }^{3}$ School of Nursing, National Defense Medical Center, Taipei, Taiwan \\ ${ }^{4}$ Department of Radiology, Tri-Service General Hospital, National Defense Medical Center, Taipei, Taiwan \\ ${ }^{5}$ Graduate Institute of Clinical Medicine and Department of Otolaryngology, College of Medicine, Taipei Medical University, Shuang \\ Ho Hospital, New Taipei City, Taiwan
}

Rhinology 52: 208-214, 2014 DOI:10.4193/Rhino13.110

*Received for publication: July 26,2013 Accepted: October 15, 2013

\begin{abstract}
Objectives: The frontal sinus has the most complex and variable drainage routes of all paranasal sinus regions. The goal of this study was to identify these anatomical factors and inflammation areas relating to chronic frontal sinusitis by comparing radiological presentations in patients with and without frontal sinusitis.
\end{abstract}

Methods: All adult patients with chronic rhinosinusitis who had received computed tomography (CT) scans of the nasal cavities and paranasal sinuses between October 2010 and September 2011. Logistic regression analysis was used to compare the distribution of various frontal recess cells and surrounding inflammatory conditions in patients with and without frontal sinusitis.

Results: Analysis of 240 sides of CT scans was performed with 66 sides excluded. The opacification of the frontal recess and sinus lateralis demonstrated a strong association with an increased presence of frontal sinusitis by multiple logistic regression models.

Conclusion: Opacification of the frontal recess and sinus lateralis was found to be associated with a significantly increased risk of frontal sinusitis and developing severe blockage of drainage pathways. It provides evidence that mucosal inflammation disease in these two areas is a very important factor leading to chronic frontal sinusitis.

Key words: sinusitis, computed tomography, frontal sinus, frontal recess, frontal recess cells, sinus lateralis, mucosal disease

\section{Introduction}

Although transnasal endoscopic sinus instrumentation has been in use for around three decades, management of frontal sinus diseases remains the most challenging topic in all paranasal sinuses. Accurate understanding the pathophysiological process of chronic frontal sinusitis requires a thorough knowledge of the complex anatomy and physiology. The frontal sinus has the most complex and variable drainage of all paranasal sinus regions, and multiple drainage routes are commonly seen in the frontal sinus. From the frontal recess, secretions drain into the middle meatus via one of two major drainage routes. In approximately $40 \%$ of cases, secretions from the frontal recess drain posteroinferiorly into the ethmoid infundibulum and subsequently into the middle meatus through the hiatus semilunaris ${ }^{(1)}$. In the remaining cases, the frontal recess drains into the middle meatus. In accessory drainage pathways, when the bulla lamella is not attached to the skull base, the frontal sinus can drain directly into the suprabullar recess and finally connect to the nasal cavity ${ }^{(2-5)}$.

The frontal recess between the sinus and the anterior middle 
meatus is shaped approximately like an upright funnel with the apex at the frontal ostium. A number of cells that can impinge the frontal recess and induce frontal sinusitis have been classified and are termed frontal recess cells ${ }^{(6)}$ (Figures 1 and 2). These include agger nasi cells (ANC), supraorbital ethmoid cells (SBC), frontal cells (FC) type 1 to 4 , frontal bulla cells (FBC), suprabullar cells (SBC), interfrontal sinus septal cells (IFSSC), and recessus terminalis (RT) according to the classification of Bent et al. ${ }^{(7)}$. In addition, the sinus lateralis (also called the suprabullar and retrobullar recess) also has an important relationship with the frontal recess ${ }^{\left({ }^{8}\right)}$. The clinical relevance of these cells lies in their potential to cause frontal sinusitis by obstructing frontal sinus outflow.

Various conditions and environmental factors can predispose a person to develop sinusitis. Anatomical variations including concha bullosa, uncinate process abnormalities, Haller cells, and septal deviation (SD) have been proposed to participate in impairing drainage leading to stasis of secretions and bacterial overgrowth. Moreover, there is a strong correlation between sinusitis and exogenous inflammatory events such as allergens, irritants, viruses, bacteria, and fungi ${ }^{(9)}$. Any inflammatory process, such as mucosal oedema or polyps, can potentially impair normal drainage and ventilation of the sinuses leading to ostial obstruction. Differences in the frontal sinus drainage pathway (FSDP) determine the likelihood of the frontal sinus being affected by the accompanying obstruction of the ostiomeatal complex (OMC) and secondary infection in the maxillary sinuses (10).

Although many anatomical and radiological studies have demonstrated the drainage pattern of the frontal sinus ${ }^{(3,10-14)}$, little has been reported regarding the association between mucosal
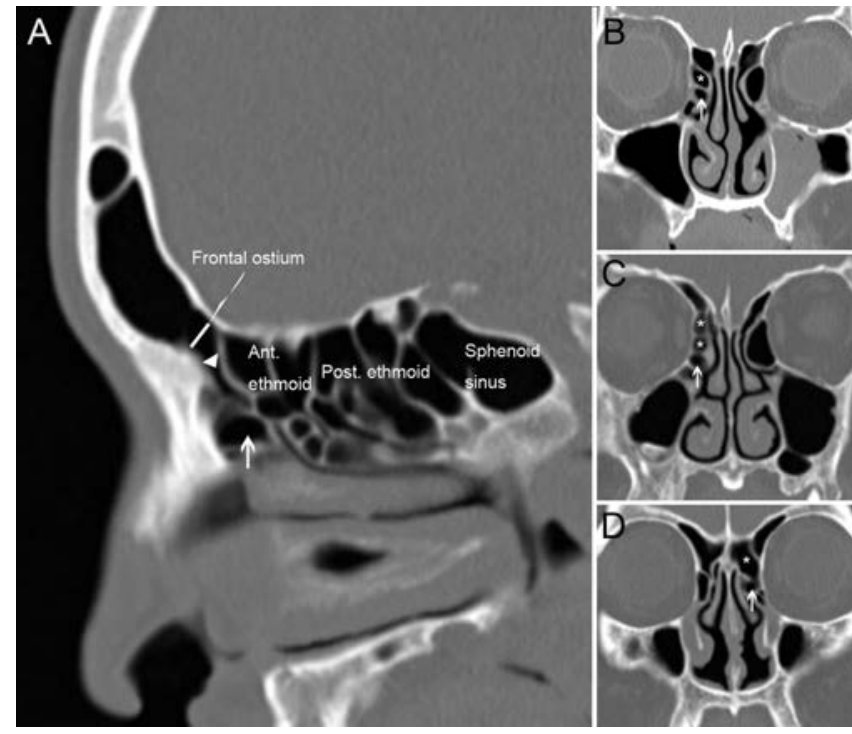

Figure 1. (A) Sagittal computed tomography image demonstrating the surrounding structures of frontal recess (white arrow head) and the agger nasi cell (ANC) (white arrow). Each frontal cell (FC) is shown as asterisk (*) at (B) FC type 1, (C) FC type 2 and (D) FC type 3 on the coronal view.

disease and the presence of frontal sinusitis. The frontal recess has been extensively discussed as a major cause of failed endoscopic sinus surgery ${ }^{(15)}$. Therefore, the aim of this study was to identify the anatomical factors and inflammatory areas relating to chronic frontal sinusitis by comparing the radiological presentations in patients with and without frontal sinusitis.

\section{Materials and methods}

The study was reviewed and approved by the Institutional Re-
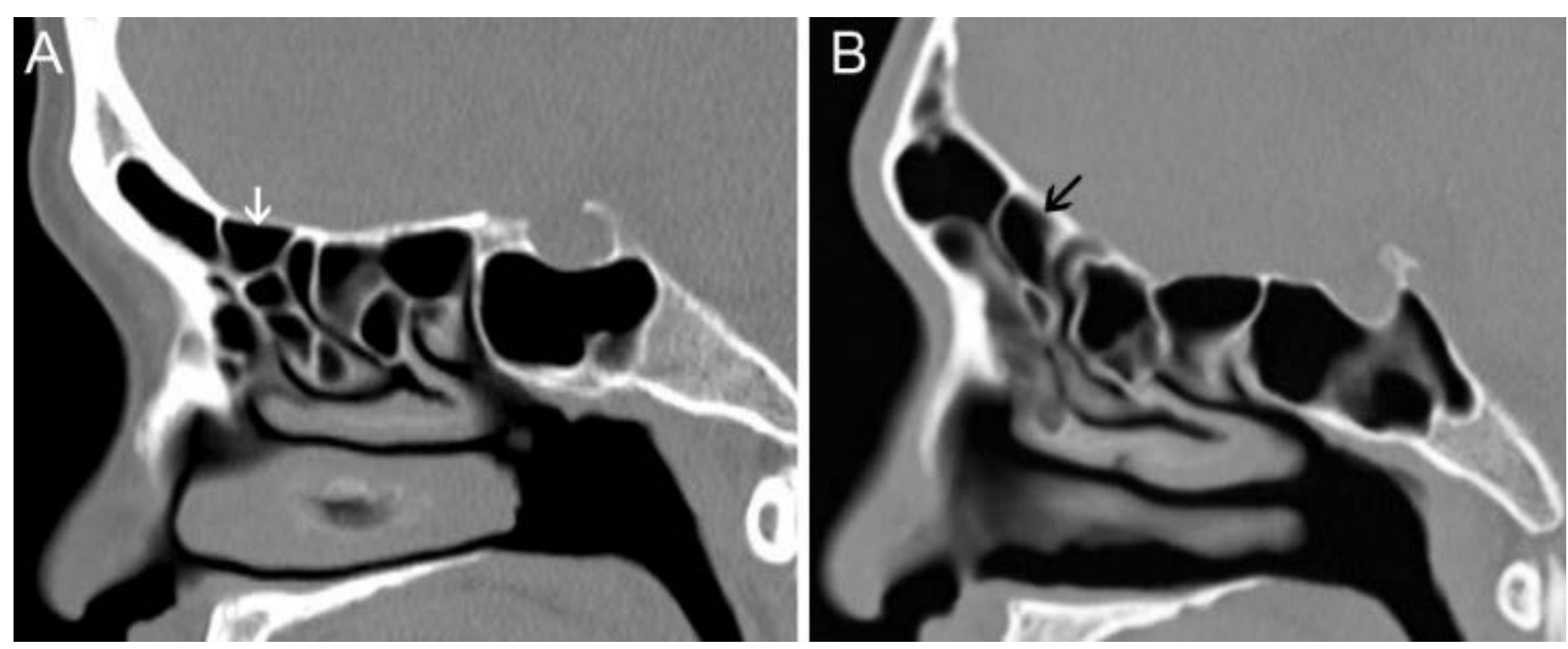

Figure 2. Sagittal computed tomography images showed the suprabullar cell (SBC) and frontal bullar cell (FBC). (A) A SBC (white arrow) is pneumatized from the anterior ethmoid cell, and its superior and posterior margin is the anterior cranial base. (B) A FBC (black arrow) pneumatizes along the skull base and extends into the frontal sinus on this sagittal scan. 
view Board of the Tri-Service General Hospital-National Defense Medical Center (TSGHIRB No.: 1-102-05-031). This study was performed in a tertiary care academic medical center. A review was performed of consecutive paranasal CT scans retrospectively.

\section{Inclusion criteria}

All patients 18 years and older with the diagnosis of chronic rhinosinusitis underwent $\mathrm{CT}$ scans of the paranasal sinuses. The diagnosis of chronic rhinosinusitis was fit in with the diagnosis criteria from American Academy of Otolaryngology-Head and Neck Surgery ${ }^{(16)}$. The definition of chronic rhinosinusitis is as follows: "Twelve weeks or longer of two or more of the following signs and symptoms including mucopurulent drainage (anterior, posterior, or both), nasal obstruction (congestion), facial painpressure-fullness, or decreased sense of smell. Inflammation is documented by one or more of the following findings including purulent mucus or oedema in the middle meatus or ethmoid region, polyps in nasal cavity or the middle meatus, and/or radiographical imaging showing inflammation of the paranasal sinuses."

\section{Exclusion criteria}

Patients who had trauma or prior surgery of the bilateral sinuses and nose, diffuse sinonasal polyposis, age younger than 18 years, incomplete CT sections, frontal sinus mucocele, fibroosseous lesions, and sinonasal malignancy were excluded from this study. Fifty one patients were excluded from this study. The operated sides were excluded in the patients undergoing unilateral sinonasal surgery prior to receiving $\mathrm{CT}$ scans.

\section{Data collection}

We retrospectively identified 120 consecutive patients with chronic rhinosinusitis who had received computed tomography (CT) scans of the nasal cavities and paranasal sinuses between October 2010 and September 2011. All CT scans were obtained by a multiple detector scanner (Philips Brilliance 64-slice CT scanner, Philips Medical Imaging, Best, the Netherlands) with contiguous axial cuts of $1 \mathrm{~mm}$ thickness. The data were then reconstructed into coronal and sagittal images on a computer workstation.

All of the CT scans were analyzed jointly by three authors (an attending otolaryngologist Dr. Shih, a resident otolaryngologist Dr. Lai, and an attending radiologist Dr. Lee). Each side of the patients' frontal sinuses (hereafter referred to as sides) was evaluated separately. We discussed about the relevant features of the scans, and made a final decision about the presence or absence of a particular anatomical structure or frontal sinus mucosal thickening. The data were used to determine the incidence of anatomical variables, mucosal thickening of all paranasal sinuses, and calculations relating to the associations between these elements. Opacification, air-fluid level, and/or mucosal thickening greater than $3 \mathrm{~mm}$ involving the entire sinus or the dependent portions of the frontal sinus were interpreted as frontal sinusitis. To stratify the severity of frontal sinusitis, it was classified as partial or complete opacification of the frontal sinus based on the Lund-Mackay CT staging system ${ }^{(5)}$. The frontal recess cells were classified according to the criteria defined by Lee et al. ${ }^{(12)}$. The anterior-posterior (A-P) diameter of the frontal ostium was determined by identifying the sagittal CT section with the shortest distance between the nasofrontal beak and the junction between the posterior table of the frontal sinus with the anterior skull base. The length of the line perpendicular to the junction and passing to the nasofrontal beak was defined as the A-P diameter of the frontal ostium, and a built-in ruler on the marking cross was used to measure it. The A-P diameter of the frontal recess was determined as the shortest distance from the ANC/FC/nasofrontal beak anteriorly to the ethmoid bulla/ bulla lamella/SBC/FBC posteriorly on the same sagittal plane as the A-P diameter of the frontal ostium.

\section{Statistical analyses}

A power calculation based on current data indicated that 64 patients ( 128 sides) would be required for review to allow for an adequately powered study (power $=0.8 ; a=0.05$ ). Numeric variables were presented as total numbers, percentages, and mean values. Statistical analysis was performed using the chisquared test for categorical variables and ANOVA for continuous variables. Two-tailed tests were performed for each scenario and the significance level was set at $p<0.05$. All analyses were performed using SPSS software version 17.0 for Windows (SPSS Inc., Chicago, IL, USA). Univariate and multivariate logistic regression analyses were performed to identify the factors linked with frontal sinusitis. Odds ratios (OR) and $95 \%$ confidence intervals $(\mathrm{Cl})$ were calculated for each factor. A independent ttest was conducted to compare the differences of A-P Diameters between frontal ostium and frontal recess on the development of frontal sinusitis. The predictor variables were classified into 2 categories: the anatomical factors included SD, ANC, FC1 to 4, SBC, FBC, SOEC, IFSSC and RT; and the mucosal inflammation factors included the opacification of the frontal recess, sinus lateralis, OMC, maxillary and anterior ethmoid sinuses.

\section{Results}

A total of 188 sides from 94 patients were evaluated. The study group was comprised of 57 men and 37 women with a mean age of $46.38 \pm 17.85$ years (range 18 to 85 years). We were able to identify the frontal recess cells in 174 (92.5\%) of the 188 sides. In the other 14 (7.5\%) sides, the cells were either unidentified or satisfied any of the exclusion criteria. The prevalence of ANC was $90.8 \%$ (158 sides). FC type 1 to 4 were identified in 62 sides (35.6\%), 19 sides (10.9\%), 12 sides (6.9\%), and 2 sides (1.1\%), respectively. SBC, FBC, SOEC, IFSSC, and RT were identified 
Table 1. Association between anatomical factors and the development of frontal sinusitis.

\begin{tabular}{|c|c|c|c|c|c|}
\hline \multirow{2}{*}{ Variables } & \multirow{2}{*}{$\begin{array}{l}\text { Frontal } \\
\text { sinusitis } \\
n=66, \\
\text { No. }(\%)\end{array}$} & \multirow{2}{*}{$\begin{array}{c}\text { No } \\
\text { frontal } \\
\text { sinusitis } \\
n=108, \\
\text { No. (\%) }\end{array}$} & \multicolumn{3}{|c|}{ Univariate analysis } \\
\hline & & & OR & $95 \% \mathrm{Cl}$ & $p$-value \\
\hline SD & $18(27.3)$ & $17(15.7)$ & 2.01 & $0.94-4.25$ & 0.07 \\
\hline ANC & $61(92.4)$ & $95(88.0)$ & 1.67 & $0.57-4.92$ & 0.35 \\
\hline FC1 & $22(33.3)$ & $40(37.0)$ & 0.85 & $0.45-1.62$ & 0.62 \\
\hline FC2 & $5(7.6)$ & $14(13.0)$ & 0.42 & $0.13-1.33$ & 0.13 \\
\hline FC3 & $3(4.5)$ & $9(8.3)$ & 0.53 & $0.14-2.01$ & 0.34 \\
\hline FC4 & $2(3.0)$ & $3(2.8)$ & 1.09 & $0.18-6.72$ & 0.92 \\
\hline SBC & $36(54.5)$ & $44(40.7)$ & 1.75 & $0.94-3.24$ & 0.08 \\
\hline FBC & $9(13.6)$ & $17(15.7)$ & 0.85 & $0.35-2.02$ & 0.43 \\
\hline SOCE & 0 & $1(0.9)$ & 0.99 & $0.98-1.01$ & 0.44 \\
\hline RT & $2(3.0)$ & $2(1.9)$ & 1.66 & $0.23-12.5$ & 0.62 \\
\hline IFSSC & $7(10.6)$ & $9(8.3)$ & 1.29 & $0.46-3.65$ & 0.68 \\
\hline
\end{tabular}

$\mathrm{OR}=$ odds ratios; $\mathrm{Cl}=$ confidence interval; $\mathrm{SD}=$ septal deviation; $\mathrm{ANC}=$ agger nasi cell; FC 1 to 4 = frontal cells types 1 to 4 ; IFSSC = interfrontal sinus septal cell; SBC = suprabullar cell; SOEC = supraorbital ethmoid cell; FBC = frontal bullar cell; RT = recessus terminalis.

Table 2. Comparison of anterior-posterior diameters of frontal ostium and frontal recess between the patients with and without frontal sinusitis.

\begin{tabular}{|lccc|}
\hline & $\begin{array}{c}\text { Mean A-P } \\
\text { Diameter with } \\
\text { Frontal } \\
\text { sinusitis }(\mathrm{mm})\end{array}$ & $\begin{array}{c}\text { Mean A-P } \\
\text { Diameter with- } \\
\text { out Frontal } \\
\text { sinusitis }(\mathrm{mm})\end{array}$ & p-value \\
\hline Frontal ostium & $6.20 \pm 1.82$ & $6.81 \pm 1.76$ & 0.03 \\
\hline Frontal recess & $1.50 \pm 0.42$ & $2.32 \pm 0.70$ & $<0.01$
\end{tabular}

$\mathrm{A}-\mathrm{P}=$ anterior-posterior.

in 92 sides (52.9\%), 26 sides (14.9\%), 6 sides (3.4\%), 16 sides (9.2\%), and 24 sides (13.8\%), respectively. Sixty-four sides were diagnosed as having frontal sinusitis, of which 38 sides were completely opaque and 26 sides partially opaque. The anatomical factors were analyzed in patients with and without frontal sinusitis (Table1). There were no significant differences in SD and all frontal recess cells in the patients with frontal sinusitis compared to those without frontal sinusitis. A significant correlation between a higher incidence of frontal sinusitis and shorter A-P diameters of the frontal recess was found (Table 2 ).
Table 3. Association between inflammation in different areas and the development of frontal sinusitis.

\begin{tabular}{|c|c|c|c|c|c|c|}
\hline \multirow{2}{*}{$\begin{array}{l}\text { Opacifica- } \\
\text { tion } \\
\text { area }\end{array}$} & \multirow{2}{*}{$\begin{array}{l}\text { Frontal } \\
\text { sinusitis } \\
n=66 \text {, } \\
\text { No. }(\%)\end{array}$} & \multirow{2}{*}{$\begin{array}{c}\text { No } \\
\text { Frontal } \\
\text { sinusitis } \\
n=108, \\
\text { No. (\%) }\end{array}$} & \multicolumn{2}{|c|}{$\begin{array}{c}\text { Univariate } \\
\text { analysis }\end{array}$} & \multicolumn{2}{|c|}{$\begin{array}{c}\text { Multivariate } \\
\text { Analysis }\end{array}$} \\
\hline & & & OR & $\begin{array}{c}\text { p- } \\
\text { value }\end{array}$ & OR & $\begin{array}{c}\text { p- } \\
\text { value }\end{array}$ \\
\hline OMC & $55(83.3)$ & $49(45.4)$ & 6.02 & $<0.01$ & 3.44 & 0.18 \\
\hline $\begin{array}{l}\text { Maxillary } \\
\text { sinus }\end{array}$ & $43(65.2)$ & $50(46.3)$ & 2.17 & 0.02 & 0.44 & 0.29 \\
\hline Ant eth sinus & 57 (86.4) & 33 (30.6) & 14.39 & $<0.01$ & 1.06 & 0.94 \\
\hline $\begin{array}{l}\text { Frontal } \\
\text { recess }\end{array}$ & 61 (92.4) & $27(25.0)$ & 36.60 & $<0.01$ & 28.86 & $<0.01$ \\
\hline $\begin{array}{c}\text { Sinus } \\
\text { lateralis }\end{array}$ & $37(56.1)$ & $9(8.3)$ & 14.03 & $<0.01$ & 5.45 & $<0.01$ \\
\hline
\end{tabular}

$\mathrm{OMC}=$ ostiomeatal complex; $\mathrm{OR}=$ odds ratio; $\mathrm{Cl}=$ confidence interval; Ant eth $=$ anterior ethmoid.

Table 4. Comparison of percentage of anatomical variants indentified on computed tomographic images from case series of Asian frontal anatomy in English literature.

\begin{tabular}{|c|c|c|c|c|}
\hline Cell types & $\begin{array}{c}\text { Ours } \\
174 \text { Sides, } \\
\text { No. }(\%)\end{array}$ & $\begin{array}{c}\text { Lien } \\
\text { et al. }{ }^{(13)} \text {, } \\
363 \text { Sides, } \\
\text { No. }(\%)\end{array}$ & $\begin{array}{c}\text { Han } \\
\text { et al. }{ }^{(27)} \text {, } \\
404 \text { Sides, } \\
\text { No. }(\%)\end{array}$ & $\begin{array}{c}\text { Cho } \\
\text { et al. }{ }^{(28)} \text {, } \\
114 \text { Sides, } \\
\text { No. (\%) }\end{array}$ \\
\hline ANC & 158 (90.8) & $323(89.0)$ & $380(94.1)$ & 107 (94.0) \\
\hline FC1 & $62(35.6)$ & $78(21.5)$ & $98(24.4)$ & $26(22.8)$ \\
\hline FC2 & 19 (10.9) & 38 (10.5) & $28(7.0)$ & $16(14.0)$ \\
\hline FC3 & $12(6.9)$ & $28(7.7)$ & $33(8.2)$ & $9(7.9)$ \\
\hline FC4 & $2(1.1)$ & $0(0)$ & $0(0)$ & $0(0)$ \\
\hline SBC & $92(52.9)$ & $142(39.1)$ & $148(36.6)$ & $45(39.5)$ \\
\hline FBC & 26 (14.9) & $23(6.3)$ & $36(9.0)$ & $16(14.0)$ \\
\hline SOCE & $6(3.4)$ & $28(7.7)$ & $22(5.4)$ & $3(2.6)$ \\
\hline RT & $24(13.8)$ & $159(43.8)$ & $360(89.1)$ & $76(66.7)$ \\
\hline IFSSC & $16(9.2)$ & $35(9.6)$ & $25(12.4)$ & $10(8.8)$ \\
\hline Race & Taiwanese & Taiwanese & Chinese & Korea \\
\hline
\end{tabular}

$\mathrm{OR}=$ odds ratios; $\mathrm{Cl}=$ confidence interval; $\mathrm{SD}=$ septal deviation; $\mathrm{ANC}=$ agger nasi cell; FC 1 to 4 = frontal cells types 1 to 4 ; IFSSC = interfrontal sinus septal cell; SBC = suprabullar cell; SOEC = supraorbital ethmoid cell; $\mathrm{FBC}=$ frontal bullar cell; $\mathrm{RT}=$ recessus terminalis. 


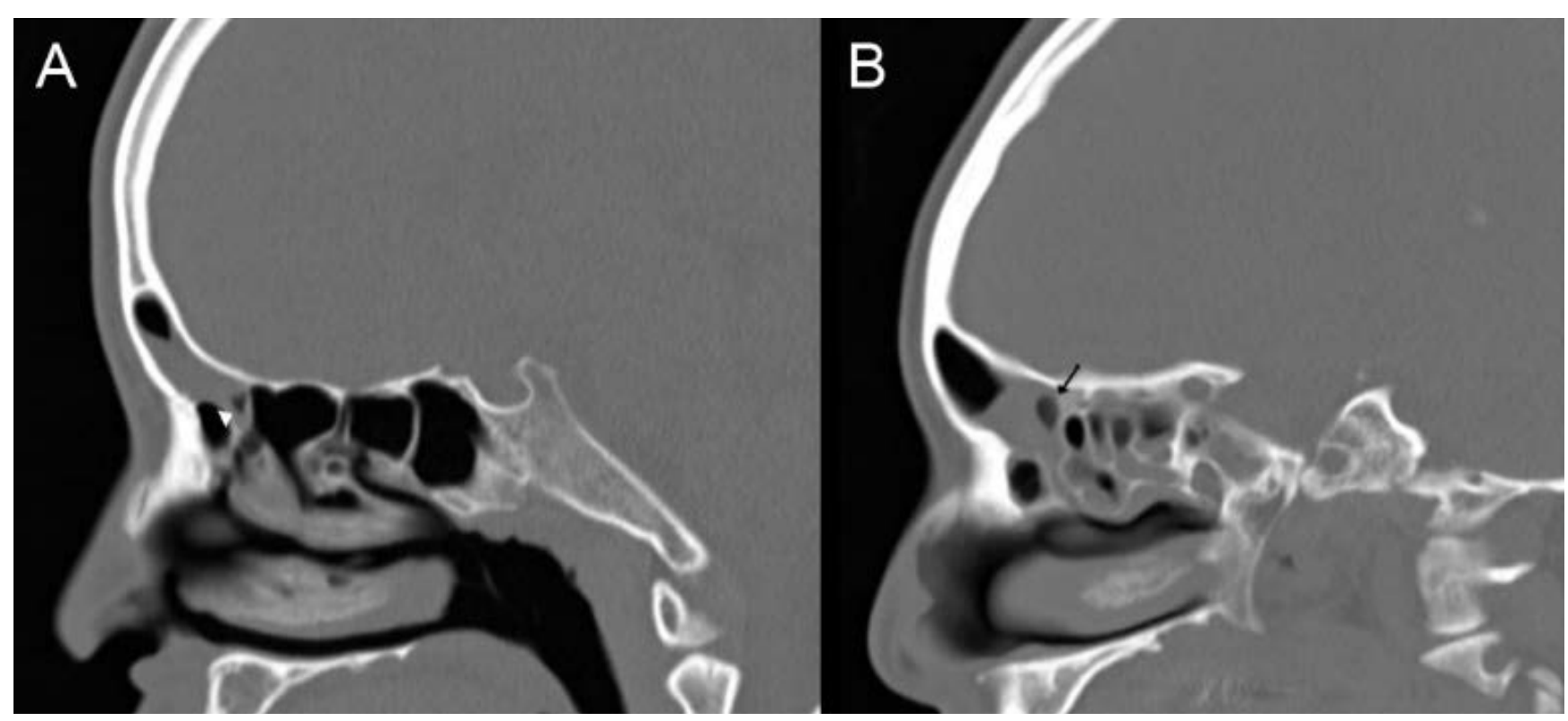

Figure 3. Sagittal computed tomography images of the patients with frontal sinusitis. (A) Opacification of the frontal recess (white arrow head) and no opacification of the sinus lateralis. (B) Concurrent opacification of the frontal recess and sinus lateralis (black arrow).

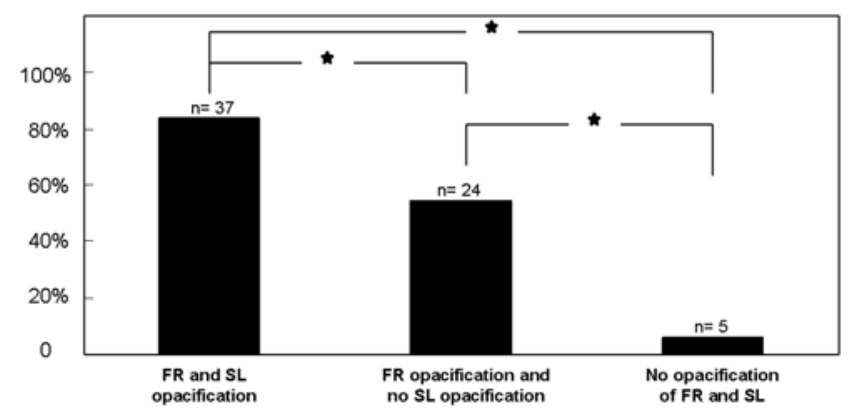

Figure 4. The ratio of the sides with frontal sinusitis to 174 sides was based on frontal recess and/or sinus lateralis opacification. The patients with concurrent opacification of the frontal recess (FR) and sinus lateralis (SL) had a higher frequency of frontal sinusitis than those with frontal recess opacification and no opacification of the sinus lateralis. ${ }^{*} p<0.01$.

\section{Comparison of mucosal inflammation factors}

Table 3 shows the association between mucosal inflammation factors and the development of frontal sinusitis The opacification of the frontal recess, sinus lateralis, OMC, maxillary and anterior ethmoid sinuses was statistically significantly associated with an increased presence of frontal sinusitis $(p<0.01)$ by univariate analysis. In multivariate analysis, the opacification of the frontal recess and sinus lateralis demonstrated a strong association with an increased frequency of frontal sinusitis $(\mathrm{p}<$ 0.01 ). Among the 44 sides with concurrent opacification of the frontal recess and sinus lateralis, 37 had frontal sinusitis (Figure $3 \mathrm{~A})$. Among the 44 sides with opacification of the frontal recess without opacification of the sinus lateralis, 24 had frontal sinusitis (Figure 3B). Among the 86 sides without opacification of the frontal recess and sinus lateralis, only 5 had frontal sinusitis.
The frequency of frontal sinusitis in concurrent opacification of the frontal recess and sinus lateralis was the highest, followed by opacification of the frontal recess and no opacification of the sinus lateralis, and without opacification of the frontal recess or sinus lateralis $(p<0.01)$ (Figure 4).

We further compared the patients with partial opacification of the frontal sinus with those with complete opacification of the frontal sinus. There was no significant difference in the presence of these anatomical and mucosal inflammation factors.

\section{Discussion}

It is widely accepted that ostial obstruction is a primary pathophysiological mechanism contributing to sinusitis. It can be caused by anatomical variations or by mucosal inflammation, and in many cases the combination of these two conditions leads to chronic infections of the paranasal sinuses or recurrence. During the past few years, a greater appreciation of the anatomy and physiology has had a major impact on the treatment for chronic sinus diseases. McLaughlin et al. reported that frontal sinus obstruction is due to narrowing of the FSDP by any of its bony surroundings, mucosal oedema, polyps, scarring, and adhesions caused by trauma, infection, or previous surgery ${ }^{(8)}$. In a study group of 384 CT scans, Lien et al. found that frontoethmoid cells (SBC, FBC, and SOEC) had a more significant association with a higher incidence of frontal sinusitis than other frontal recess cells, and that the presence of these cells may lead to narrowing of the FSDP through shortening of the A-P diameter of the frontal ostium and frontal recess ${ }^{(13)}$.

Nasal septal deviation has been reported to be a contributing factor to sinusitis ${ }^{(17)}$. The existence of SD can compromise the ipsilateral nasal air channels through mechanical obstruction, and 
result in the retention of secretions and poor ventilation of the affected sinus. Calhoun et al. studied 182 CT scans and found SD in $40 \%$ of the rhinosinusitis disease group versus $19.5 \%$ of the control group ${ }^{(2)}$. However, some authors have proposed that there is no relationship between nasal septal deviation and sinus disease ${ }^{(18)}$. Furthermore, there is some controversy about frontal cell obstruction of the frontal sinus. A previous study found that all frontal cells may develop clinical significance by becoming primarily infected or obstructing the frontal sinus, resulting in a secondary frontal sinusitis ${ }^{(19)}$. Other studies found that the existence of $\mathrm{FBC}, \mathrm{SBC}$, and SOEC might narrow the frontal sinus drainage pathway ${ }^{(13,20,21)}$. Moreover, a recent study demonstrated that a larger volume of the ANC tended to be associated with a wider anteroposterior diameter of frontal recess and ostium ${ }^{(22)}$. It is reasonable to think that a larger frontal cell or a more narrow frontal sinus drainage pathway could contribute to frontal sinusitis. Besides, in an analysis of intraoperative findings associated with frontal sinus outflow tract obstruction, Han et al. found the major causes for frontal sinusitis were polyp (53\%), frontal recess synechia (21\%), agger nasi cell (12\%), and narrow osteomeatal complex (5\%) ${ }^{(23)}$.

Our study showed the presence of SD and SBC tended to correlate with a higher frequency of frontal sinusitis, although there was no significant association between these anatomical factors and the presence of frontal sinusitis. The patients with frontal sinusitis had also shorter A-P diameters of the frontal ostium and frontal recess in comparison with those without frontal sinusitis. Therefore the anatomy involving FSDP was still a contributor to the development of chronic frontal sinusitis.

In a retrospective study that compared the anatomy of frontal cells and their relationship to frontal sinusitis in patients who had and had not received sinus surgery, the presence of frontal cells did not correlate with a greater incidence of frontal sinusitis ${ }^{(24)}$. The authors proposed that mucosal inflammation is a major factor in the pathogenesis of frontal sinusitis. Nouraei et al. evaluated 278 CT scans from chronic rhinosinusitis patients and reported that the obstruction of the OMC is a risk factor for chronic rhinosinusitis ${ }^{(25)}$. We found that there was a significant increase in the frequency of frontal sinusitis among patients with mucosal inflammation in the ipsilateral maxillary sinus, anterior ethmoidal sinus, OMC, frontal recess and sinus lateralis. Such surrounding mucosal thickening and retained fluid attributed to the occurrence of chronic frontal sinusitis. In contrast, there were no statistically significant differences in the frequency of frontal sinusitis based on the presence of anatomical variations in multivariate analysis. It suggested that mucosal inflammation disease was the most important underlying factor in the development of chronic frontal sinusitis rather than anatomical obstruction by retained cells.
Interestingly, increased opacification of the frontal recess (odds ratio, 28.86; $\mathrm{p}<0.01$ ) and sinus lateralis (odds ratio, 5.45; $\mathrm{p}<$ 0.01 ) was more strongly associated with an increasing incidence of frontal sinusitis in the multivariate analysis. The patients with concurrent opacification of the frontal recess and sinus lateralis had a higher frequency of frontal sinusitis than those with frontal recess opacification and no opacification of the sinus lateralis. The sinus lateralis opens into the frontal recess and contributes to the accessory drainage pathway of the frontal sinus ${ }^{(2-4)}$. It was demonstrated that mucosal disease in the sinus lateralis brought about blockage of the accessory drainage pathway for the frontal sinus, and that this promoted the development of frontal sinusitis. Our results showed the importance of the accessory drainage pathways, and suggested that the patients with mucosal inflammation in major and accessory pathways had a higher incidence of frontal sinusitis than those with mucosal inflammation in the major pathways. Successful endoscopic sinus surgery results from accurate imaging assessment of the sinus disease and the re-establishment of ventilation and drainage pathways via the physiological routes, the enlargement of the frontal recess and ethmoidectomy allows the diseased mucosa to return to normal on clinical grounds ${ }^{(26)}$.

There are some limitations to this study. First, this study is limited because of its retrospective character, there was no control group with a normal population of sinus CT scans for determination of the relevant anatomical variables. We compared the distribution of various frontal recess cells identified on CT images among Asian adult populations in the literature (Table 4), there was no prominent difference in the prevalences of the anatomical variants between ours and other studies $(13,27,28)$. Second, the data came from one tertiary medical center; this might limit the generalizability of the results. Third, the A-P diameters of the frontal ostium and frontal recess were only detected on the parasagittal images, and they might not exactly reflect the width in these areas.

\section{Conclusion}

In conclusion, our results provide evidence that mucosal inflammatory diseases presenting in FSDP have strong association with a higher incidence of chronic frontal sinusitis. Although anatomical variations of the frontal recess are likely to play a role in the ventilation and drainage of the sinus, there was no statistically significant relationship in patients with frontal sinusitis in our study. Opacification of the frontal recess and sinus lateralis was associated with a higher rate of frontal sinusitis, suggesting that the inflammation in these areas leads to severe blockage of drainage pathways. This is an important finding for surgeons who perform endoscopic sinus surgery. Establishing the patency of the major and accessory pathways may be necessary to treat frontal sinusitis. 


\section{Authorship contribution}

Study conception and design: LWS, YPL, WCH, WHW, SCP; Acquisition of data: LWS, LCH, LYY; Analysis and interpretation of data: LWS, YPL, SCP; Drafting of the manuscript: LWS, YPL, LWS, LCH, SCP; Critical revision: WCH, WHW, SCP.

\section{Acknowlegdement}

None

\section{Conflicts of Interest}

The authors declare no conflicts of interest.

\section{References}

1. Landsberg R, Friedman M. A computer assisted anatomical study of the nasofrontal region. Laryngoscope. 2001;111: 2125-2130.

2. Calhoun $\mathrm{KH}$, Waggenspack GA, Simpson $\mathrm{CB}$, et. al. CT evaluation of the paranasal sinuses in symptomatic and asymptomatic populations. Otolaryngol Head Neck Surg. 1991 104: 480-483.

3. Bolger WE, Mawn CB. Analysis of the suprabullar and retrobullar recesses for endoscopic sinus surgery. Ann Otol Rhino Laryngol Suppl. 2001; 186: 3-14.

4. Mann WJ, Toth M, Gouveris H, Amedee $R G$. The drainage system of the paranasal sinuses: a review with possible implications for balloon catheter dilation. Am J Rhinol Allergy. 2011; 25: 245-248.

5. Lund VJ, Kennedy DW. Quantification for staging sinusitis. The Staging and Therapy Group. Ann Otol Rhinol Laryngol Suppl. 1995; 167: 17-21.

6. Mafee MF, Chow JM, Meyers R. Functional endoscopic sinus surgery: anatomy, CT screening, indications, and complications. Am J Roentgenol. 1993; 160: 735-744.

7. Bent JP, III, Cuilty-Siller C, Kuhn FA. The frontal cell as a cause of frontal sinus obstruction. Am J Rhinol. 1994; 8: 185-191.

8. McLaughlin RB Jr, Rehl RM, Lanza DC Clinically relevant frontal sinus anatomy and physiology. Otolaryngol Clin North Am. 2001; 34: 1-22.

9. Kern RC, Conley DB, Walsh W, et al Perspectives on the etiology of chronic rhinosinusitis: an immune barrier hypothesis. Am J Rhinol. 2008; 22: 549-559.

10. Gaafar H, Abdel-Monem MH, Qawas MK Frontal sinus outflow tract "anatomic study". Acta Otolaryngol. 2001; 121: 305-309.

11. Daniels DL, Mafee MF, Smith MM, et al. The frontal sinus drainage pathway and related structures. AJNR Am J Neuroradiol. 2003; 24 1618-1627.

12. Lee WT, Kuhn FA, Citardi MJ. 3D computed tomographic analysis of frontal recess anatomy in patients without frontal sinusitis. Otolaryngol Head Neck Surg. 2004; 131:

\section{4-173.}

13. Lien CF, Weng HH, Chang YC, Lin YC, Wang $\mathrm{WH}$. Computed tomographic analysis of frontal recess anatomy and its effect on the development of frontal sinusitis. Laryngoscope 2010; 120: 2521-2527.

14. Langille M, Walters E, Dziegielewski PT, Kotylak T, Wright ED, Frontal sinus cells: identification, prevalence, and association with frontal sinus mucosal thickening. Am J Rhinol Allergy. 2012; 26: e107-110.

15. Huang BY, Lloyd KM, DelGaudio JM Jablonowski E, Hudgins PA. Failed endoscopic sinus surgery: spectrum of CT findings in the frontal recess. Radiographics 2009; 29: 177-195

16. Rosenfeld RM, Andes D, Bhattacharyya N, et al. Clinical practice guideline: adult sinusitis. Otolaryngol Head Neck Surg. 2007; 137 (3 Suppl): S1-31.

17. Caughey RJ, Jameson MJ, Gross CW, Han JK. Anatomic risk factors for sinus disease: fact or fiction? Am J Rhinol. 2005; 19: 334-339.

18. Harar RP, Chadha NK, Rogers G. The role of septal deviation in adult chronic rhinosinusitis: a study of 500 patients. Rhinology. 2004; 42: 126-130.

19. Bent JP, 3rd, Silver JR, Porubsky ES. Acute laryngeal trauma: a review of 77 patients. Otolaryngol Head Neck Surg. 1993; 109 (3 Pt 1): 441-449.

20. Zhang L, Han D, Ge W, et al. Computed tomographic and endoscopic analysis of supraorbital ethmoid cells. Otolaryngol Head Neck Surg. 2007; 137: 562-568.

21. Bradley DT, Kountakis SE. The role of agger nasi air cells in patients requiring revision endoscopic frontal sinus surgery. Otolaryngol Head Neck Surg. 2004; 131: 525-527.

22. Park SS, Yoon BN, Cho KS, Roh $\mathrm{HJ}$. Pneumatization pattern of the frontal recess: relationship of the anterior-to-posterior length of frontal isthmus and/or frontal recess with the volume of agger nasi cell. Clin Exp Otorhinolaryngol. 2010; 3: 76-83.

23. Han JK, Ghanem T, Lee B, Gross CW. Various causes for frontal sinus obstruction. Am J
Otolaryngol. 2009; 30: 80-82

24. DelGaudio JM, Hudgins PA, Venkatraman G, Beningfield A. Multiplanar computed tomographic analysis of frontal recess cells: effect on frontal isthmus size and frontal sinusitis. Arch Otolaryngol Head Neck Surg. 2005; 131: 230-235.

25. Nouraei SA, Elisay AR, Dimarco A, et al. Variations in paranasal sinus anatomy: implications for the pathophysiology of chronic rhinosinusitis and safety of endoscopic sinus surgery. J Otolaryngol Head Neck Surg. 2009; 38: 32-37.

26. Picerno NA, Bent JP. Sinus lateralis in endoscopic ethmoidectomy. Laryngoscope. 1998; 108: 1314-1319.

27. Han D, Zhang L, Ge W, Tao J, Xian J, Zhou B. Multiplanar computed tomographic analysis of the frontal recess region in Chinese subjects without frontal sinus disease symptoms. ORL J Otorhinolaryngol Relat Spec. 2008; 70: 104-112.

28. Cho JH, Citardi MJ, Lee WT, et al. Comparison of frontal pneumatization patterns between Koreans and Caucasians. Otolaryngol Head Neck Surg. 2006; 135: 780-786.

Cheng-Ping Shih, MD

Department of Otolaryngology-Head and Neck Surgery

Tri-Service General Hospital

325, Cheng-Kung Road, Sec. 2

Neihu District

Taipei 114

Taiwan

Tel: +886-2-87927192

Fax: +886-2-87927193

E-mail:

zhengping@mail.ndmctsgh.edu.tw 